\title{
CIÊNCIAS HUMANAS \\ Programa Nacional de Assistência Estudantil: Proposta de Formação Continuada aos Servidores do IFFAR ${ }^{1}$ \\ National Student Assistance Program: Proposed Continuous Training for IFFAR Servers \\ Janete Cordeiro Lorenzoni2; Maria Rute Depoi da Silva2; Fernanda Figueira Marquezan²; Eliane Aparecida Galvão²
}

\begin{abstract}
RESUMO
O artigo objetiva apresentar uma proposta de formação continuada aos servidores do Instituto Federal Farroupilha (IFFar), acerca do Programa Nacional de Assistência Estudantil (PNAES). Evidencia-se, assim, a formação dos servidores, já que tanto as atuações dos docentes quanto dos técnicos têm implicações no ensino e na aprendizagem dos estudantes do Instituto. Para tanto, optou-se pela abordagem qualitativa, por meio da pesquisa documental e bibliográfica. Inicialmente, são apresentados marcos legais e o aporte teórico de autores que versam sobre as políticas educacionais. No decorrer do texto são discutidos aspectos da formação docente, frente a um paradigma inovador, demonstrando, assim, a necessidade de que todos os sujeitos envolvidos na educação e no ensino (re)conheçam o contexto escolar em seus diversos aspectos, e, por fim, descreve-se a proposta de formação continuada aos servidores do (IFFar).
\end{abstract}

Palavras-chave: Educação Profissional, Formação Continuada, Políticas Públicas.

\begin{abstract}
The article aims to present a proposal for continuing education to the Federal Institute of Farroupilha (IFFar), about the National Program of Student Assistance (PNAES). Thus, the formation of the servers is evident, since both teachers and technicians have an impact on the teaching and learning of the Institute's students. For that, we chose the qualitative approach, through documentary and bibliographic research. Initially, legal frameworks and the theoretical contribution of authors that deal with educational policies are presented. In the course of the text, aspects of teacher training are discussed, facing an innovative paradigm, thus demonstrating the need for all subjects involved in education and [re] learning to know the school context in its various aspects, finally, describes the proposal of continuous training for the (IFFar).
\end{abstract}

Keywords: Professional Education, Continuing Education, Public Policies.

\footnotetext{
${ }^{1}$ Artigo produzido no Mestrado em Ensino de Humanidades e Linguagens - Universidade Franciscana, Santa Maria/RS.

2 UFN - Universitário Franciscana - Santa Maria/RS - Brasil.
} 


\section{INTRODUÇÃO}

A formação continuada dos servidores da educação é um processo fundamental para que seja desenvolvida uma prática profissional coerente, no que diz respeito aos objetivos da instituiçã̃o a que se está vinculado, e ser da mesma forma condizente com a realidade em que se está inserido. Diante deste aspecto, a temática abordada neste artigo procura destacar a importância de os servidores que pertencem ao Instituto Federal Farroupilha (IFFar) conhecerem as políticas e programas de que a instituição participa e implementa, neste caso específico, o Programa Nacional de Assistência Estudantil (PNAES).

A criação dos Institutos Federais de Educação, Ciência e Tecnologia, fez parte do processo de reformulação da Rede Federal, iniciado em 2008, assim, pode-se afirmar que estas instituições se encontram em uma trajetória ainda muito recente. Da mesma forma, o quadro de servidores, em sua maioria, com pouca ou nenhuma experiência e conhecimento do serviço público, como também dos objetivos e da proposta de atuação de tais estabelecimentos de ensino.

Diante de tais aspectos, e frente à diversidade de políticas e programas implementados e desenvolvidos na instituição, percebem-se discursos e práticas contraditórios, que necessitam de conhecimento e compreensão para que estejam de acordo com os princípios institucionais que normatizam os IFs. É de extrema relevância que todos os servidores, sejam eles docentes, técnicos, efetivos ou terceirizados, tenham clareza de que desempenham suas funções em um espaço educativo, de formação de sujeitos, onde os atores principais e o objetivo maior da instituição são os estudantes.

Nesse sentido, em um primeiro momento este texto objetiva apresentar como a Educação Profissional se estruturou na sociedade brasileira, até chegar à criação dos Institutos Federais de Educação, e mais especificamente o Instituto Federal Farroupilha (IFFar), pontuando as políticas públicas que perpassaram estes processos históricos. Em seguida apresenta o PNAES, a fim de demonstrar como este programa foi conquistado e o quanto ele pode ser relevante para o acesso, a permanência e êxito dos estudantes.

Na sequência, o texto aborda a formação de professores, frente a um paradigma inovador, com destaque para a defesa de uma formação continuada que contemple todos os servidores ligados ao ensino, visto que a educação é construída por diversos atores, gestores, comunidade, docentes, técnicos e estudantes. Para finalizar, este artigo apresenta uma proposta de formação continuada para os servidores do IFFar, principalmente os que desempenham suas funções no ensino, tendo como temática central o PNAES. Tal proposição baseia-se no fato de que é de extrema importância que os servidores conheçam este Programa, como o mesmo é implementado na instituição, o público a que se destina e com que objetivos, para que se compreendam de fato a missão e os princípios que norteiam a instituição e que também se considere em suas práticas o quanto o programa pode representar na vida dos sujeitos contemplados.

\section{MARCOS LEGAIS: UMA BREVE CONTEXTUALIZAÇÃO HISTÓRICA DAS POLÍTICAS EDUCACIONAIS DA EDUCAÇÃO PROFISSIONAL}

A educação brasileira na Primeira República (1889-1930) foi marcadamente influenciada pelo positivismo, filosofia que defendia uma educação laica, maior oferta de educação escolar pública e 
uma educação científica em substituição à clássica e à literária. Com o fim da escravidão um novo problema social se apresentou, na medida em que os ex-escravos, entre outros "desvalidos", não encontravam meios para garantir a sua subsistência. É neste cenário que, em 1909, o governo Nilo Peçanha cria 19 Escolas de Aprendizes e Artífices, oficializando o estabelecimento da Rede Federal de Educação Profissional no país (BRASIL, 2014).

Com o processo de industrialização no país, o setor industrial brasileiro passa por mudanças significativas, principalmente a partir dos anos de 1950. Pode-se evidenciar que a internacionalização da necessidade de qualificação da mão de obra passa a ser prioridade. Deste modo, acontecem a ampliação da Rede Federal e o estabelecimento de acordos internacionais, como os acordos MECUSAID $^{3}$, que impulsionam a expansão da oferta de Educação Profissional.

A consolidação da indústria nacional, na Segunda República (1930-1964), ocasiona a substituição do modelo agrário-exportador pelo nacional-desenvolvimentista, seguida pela abertura do Brasil à entrada do capital internacional, no governo de Juscelino Kubitschek. Com o início da Ditadura Militar, em 1964, mantém-se a articulação entre os interesses do capital internacional e da elite política nacional. Diante disso, a elevação da escolaridade dos trabalhadores passa a ser condicionante para o desenvolvimento industrial do país (TAVARES, 2012).

A chegada de uma parcela cada vez maior da população ao ensino secundário, de acordo com Tavares (2012), ocasiona uma forte pressão por parte destes estudantes pelo acesso ao ensino superior, em busca de ascensão social. O ensino profissionalizante, muito mais do que qualificar mão de obra para a indústria, atua diminuindo a pressão exercida pela sociedade por vagas nas universidades públicas. Já que, no período da Ditadura Militar (1964-1984), o maior acesso à universidade pela população representaria o risco de se agravar o movimento, já existente, de contestação ao regime político.

A dualidade da educação que esteve presente desde o início da organização da educação brasileira (LIBÂNEO, 2012) tem na Lei de Diretrizes e Bases da Educação (LDBEN), Lei n o 4.024/61 (BRASIL, 1961) a primeira tentativa de equivalência entre ensino técnico e ensino propedêutico, pois os egressos do ensino secundário do ramo profissionalizante também poderiam ascender ao ensino superior. Porém, um egresso de curso técnico poderia prestar exames somente para cursos superiores relacionados à sua formação técnica, já aqueles que cursavam o ensino propedêutico poderiam escolher livremente qual carreira seguir (TAVARES, 2012).

Com o discurso de uma escola única para ricos e pobres, a Reforma do Ensino de $1^{\circ}$ e $2^{\circ}$ Graus, Lei no 5.692/71 (BRASIL, 1971), tornou obrigatória a profissionalização dos estudantes do ensino secundário. Contudo, a falta de condições materiais para concretizar este objetivo fez com que esta Lei ampliasse ainda mais as diferenças entre as escolas de ricos e pobres e a distância entre educação propedêutica e profissional. A grande maioria das escolas não deu conta de atender a nenhum dos propósitos do ensino secundário, nem propedêutico, nem profissionalizante (TAVARES, 2012).

Ainda de acordo com Tavares (2012), em 1982 o Estado retoma a possibilidade de as escolas optarem entre a oferta de ensino propedêutico ou técnico-profissionalizante, por meio da Lei no 7.044/82

\footnotetext{
${ }^{3}$ Acordos firmados nos anos de 1960 entre o Ministério da Educação (MEC) e a United States Agency for International Development (USAID), com o objetivo de estabelecer convênios de assistência técnica e cooperação financeira à educação brasileira. Para mais informações, consultar Arapiraca (1982).
} 
(BRASIL, 1982). Apesar de anunciada, a criação de uma escola única para todos, que unificasse educação propedêutica e profissional, não foi concretizada nesse período.

Na década de 80, com a redemocratização do Brasil, em 1985, inicia-se o processo de Reforma do Estado, sob influência da lógica neoliberal ${ }^{4}$ (PERONI, 2010). A expansão da educação ocorre prioritariamente na rede privada, enquanto que a rede pública passa por um processo estagnação, acompanhada pela terceirização de serviços e o pagamento de taxas em instituições de ensino públicas, além de algumas tentativas de privatização do ensino público. Na década de 90, o governo Fernando Henrique Cardoso realiza mudanças profundas na legislação educacional que regulamenta o Ensino Profissionalizante, com objetivos claros de reduzir os gastos públicos e favorecer que este ramo de ensino seja contemplado pela rede privada (SGUISSARDI, 2011).

Essas mudanças no campo da educação seguem a lógica do mercado liberal. Após a criação dos Estados-Nações, em que o poder público tinha um papel central e dominante nos primeiros sistemas escolares, passa-se a buscar a lucratividade deste setor por meio da privatização.

Pelo exposto, é possível verificar que com as transformações econômicas, a ascensão do liberalismo, como também do capitalismo, o setor educacional segue cada vez mais a lógica do mercado, ou seja, é um campo destinado à obtenção de lucros. Para tanto, se reduz a responsabilidade do Estado com a formação dos cidadãos e passa-se a abrir um espaço cada vez mais amplo para a iniciativa privada.

A década de 90, marcada pela chamada Reforma do Estado, segundo Tavares (2012) baseia-se no sucateamento e na privatização de instituições estatais, assim como na terceirização de serviços públicos essenciais. No Brasil, nesse período, o desemprego e a inflação são os grandes desafios a serem enfrentados pelo Estado. Ao mesmo tempo, as transformações no mundo do trabalho e os avanços tecnológicos são as justificativas usadas para promover reformas educacionais profundas, quase sempre financiadas por organismos financeiros internacionais (TAVARES, 2012).

Assim, a educação consolida-se como mais um setor empresarial, com destaque para a expansão do ensino superior privado, e mais uma vez mantém-se o fosso educacional entre uma escola para ricos e uma escola para pobres. Como bem exemplifica Akkari (2011):

A concorrência entre o público e o privado, incentivada pelas escolhas dos pais e dos alunos, juntamente com um financiamento proporcional ao número de alunos, introduz práticas abertas, mas também dissimuladas, de seleção dos melhores. Estes processos podem levar à segregação e homogeneização da população segundo a rede escolar. Crescentes disparidades entre categorias socioeconômicas podem aparecer e ter efeitos significativos sobre a igualdade de acesso à Educação (p. 56).

Diante do exposto, pode-se inferir que a privatização do sistema educacional tende a manter ou até mesmo aumentar as desigualdades sociais, visto que restringe a uma parcela muito específica da sociedade o acesso à educação. Prova disso, ainda é o elevado número de ingressos nas universidades públicas oriundos de escolas privadas, ainda que hoje já se percebam algumas mudanças neste panorama.

\footnotetext{
${ }^{4} \mathrm{O}$ neoliberalismo defende claramente o Estado mínimo e a privação de direitos, além de penalizar a democracia, por considerá-la prejudicial aos interesses do mercado (PERONI, 2010).
} 
Nesse sentido, percebe-se que historicamente a educação profissional brasileira, por meio da legislação e das políticas implementadas até então, percorreu um processo marcadamente ideológico de formação de mão de obra em atendimento, muitas vezes, aos interesses econômicos e políticos, em âmbito nacional e internacional. É difícil, como explicitado no decorrer deste tópico, encontrar na história de sua constituição o interesse político na formação integral, ou seja, o acesso tanto ao ensino técnico quanto ao conhecimento propedêutico. Uma educação integral, para incluir e não segmentar, uma educação para formar, além de técnicos qualificados, cidadãos brasileiros conscientes, parece não ter estado na pauta das discussões dos legisladores.

\subsection{Os Institutos Federais de Educação: continuidade ou avanços?}

Na primeira década do século XXI, o Estado brasileiro, tendo em vista a composição de um novo governo, de caráter mais democrático-popular, implementa algumas medidas que seguem na contramão das políticas neoliberais do período anterior, com destaque para a retomada do investimento público nas instituições de ensino federais. Mas, a despeito da implantação de novas escolas técnicas e universidades federais pelo Brasil, a ampliação do atendimento continua ocorrendo predominantemente na rede privada (BRASIL/MEC/INEP, 2015).

No entanto, cabe enfatizar que o período que abrange maiores investimentos nas instituições federais de ensino também é marcado pela profunda reformulação da Rede Federal. Além da implantação de novas unidades de ensino, a Lei no 11.892/08 institui a Rede Federal de Educação Profissional, Científica e Tecnológica, ao mesmo tempo em que cria os Institutos Federais de Educação, Ciência e Tecnologia (IFs) (BRASIL, 2008), muitos dos quais são o resultado da mescla de Escolas Técnicas Federais pré-existentes, que juntas passam a integrar uma única autarquia. Apesar de manter, por força desta Lei, a oferta de ensino técnico-profissionalizante, estas novas instituições passam a concorrer com as universidades federais na oferta de ensino superior público e gratuito. 0 diferencial em relação às universidades, segundo a SETEC, é priorizar a oferta de cursos superiores de licenciatura (formação de professores), cursos de bacharelado e de tecnologia em áreas consideradas estratégicas, do ponto de vista econômico (BRASIL, 2016).

O governo Lula, de acordo com Tavares (2012), que posteriormente foi sucedido pela Presidenta Dilma Rousseff, caracterizou-se pelo grande volume de programas sociais voltados às camadas mais populares da população. Apesar de pertencerem a um partido de esquerda, estes governos mantiveram a transferência de serviços essenciais à população, como educação, por exemplo, para a iniciativa privada. Se antes prevaleciam as privatizações, agora se estabelecem parcerias públicoprivadas, mediante o repasse de verbas públicas para que empresas privadas exerçam algumas das funções do Estado, como continua ocorrendo com o ProUni e com a criação do PRONATEC (BRASIL/MEC/PRONATEC, 2016).

Cabe ainda ressaltar que, nesse período, é extinto o dispositivo legal que proibia a instalação de novas escolas técnicas mantidas pela União, da Lei no 9649/98 (BRASIL, 1998), e revoga-se o Decreto 2.208/97 (BRASIL, 1997), ambos do governo Fernando Henrique Cardoso, o que motivou muitas instituições a retomarem a oferta de ensino técnico integrado ao ensino médio. A Rede Federal de Educação Profissional e Tecnológica passa por uma expansão e é reconfigurada a partir da criação dos IFs. Paralelamente, ocorre um processo de expansão das universidades federais. 
De acordo com dados da Associação Nacional dos Dirigentes das Instituições Federais de Ensino Superior (ANDIFES), de 2003 a 2010, em 8 anos, foram implantadas 14 novas universidades federais. Os dados indicam que, de 1919 até 2002, em 83 anos, foram criadas 45 universidades. Cabe salientar que a criação destas 14 universidades foi parte do esforço empreendido pelo governo federal para a interiorização do ensino superior público, a integração com os países da América do Sul e do Caribe e países da lusofonia, em especial os africanos (ANDIFES, 2012).

No que diz respeito aos Institutos Federais, está entre os principais objetivos, conforme a Lei no 11.892/2008 que institui a Rede Federal de Educação Profissional, Científica e Tecnológica e cria os Institutos Federais de Educação, Ciência e Tecnologia, promover o desenvolvimento do país por meio da oferta à população de ensino, pesquisa e extensão, em sintonia com as demandas dos arranjos produtivos locais. E também formar professores para suprir a carência de profissionais habilitados enfrentada pela educação básica, sobretudo na área de Ciências, além de formar técnicos, tecnólogos e engenheiros em áreas específicas, de modo a contribuir para o desenvolvimento de setores estratégicos da economia nacional. Como exemplifica Pacheco (2010):

Quando lembramos que um Colégio Industrial português possibilitou o surgimento de um José Saramago é importante registrar que isto somente foi possível porque aquela escola possuía em seu currículo, como ele lembra, física, química, matemática, mecânica, desenho industrial, história, filosofia, português e francês, entre outras disciplinas. Nosso objetivo central não é formar um profissional para o mercado, mas sim um cidadão para o mundo do trabalho, o qual poderia ser tanto técnico, como um filósofo, um escritor ou tudo isto. Significa superar o preconceito de classe de que um trabalhador não pode ser um intelectual, um artista (PACHECO, 2010, p. 10-11).

Para tanto, os Institutos Federais preconizam a formação profissional e tecnológica para o mundo do trabalho, acompanhada da formação humana, a fim de construir um cidadão crítico e atuante na sociedade. Os Institutos Federais devem atuar em cursos técnicos (50\% das vagas), em sua maioria na forma integrada com o ensino médio, licenciaturas (20\% das vagas) e graduações tecnológicas, podendo ainda disponibilizar especializações, mestrados profissionais e doutorados voltados principalmente para a pesquisa aplicada de inovação tecnológica (PACHECO, 2010).

Os Institutos Federais, segundo Pacheco (2010), fundamentam sua organização pedagógica de forma verticalizada, ou seja, da educação básica à superior. Isto possibilita que os docentes atuem em diferentes níveis de ensino e que os discentes compartilhem os diferentes espaços de aprendizagem, permitindo o delineamento de trajetórias formativas que podem ir do curso técnico ao doutorado. Quanto à sua estrutura multicampi e à clara definição do território de abrangência das ações dos Institutos Federais, possibilitam, desta forma, o compromisso de intervenção em suas respectivas regiões, com o objetivo de identificar problemas e buscar soluções técnicas e tecnológicas para o desenvolvimento sustentável, também por meio da inclusão social. Deste modo, os cursos nas novas unidades deverão ser definidos através de audiências públicas e de escuta às representações da sociedade. 
Figura 2 - Expansão da Rede Federal de Educação Profissional, Científica e Tecnológica - em unidades

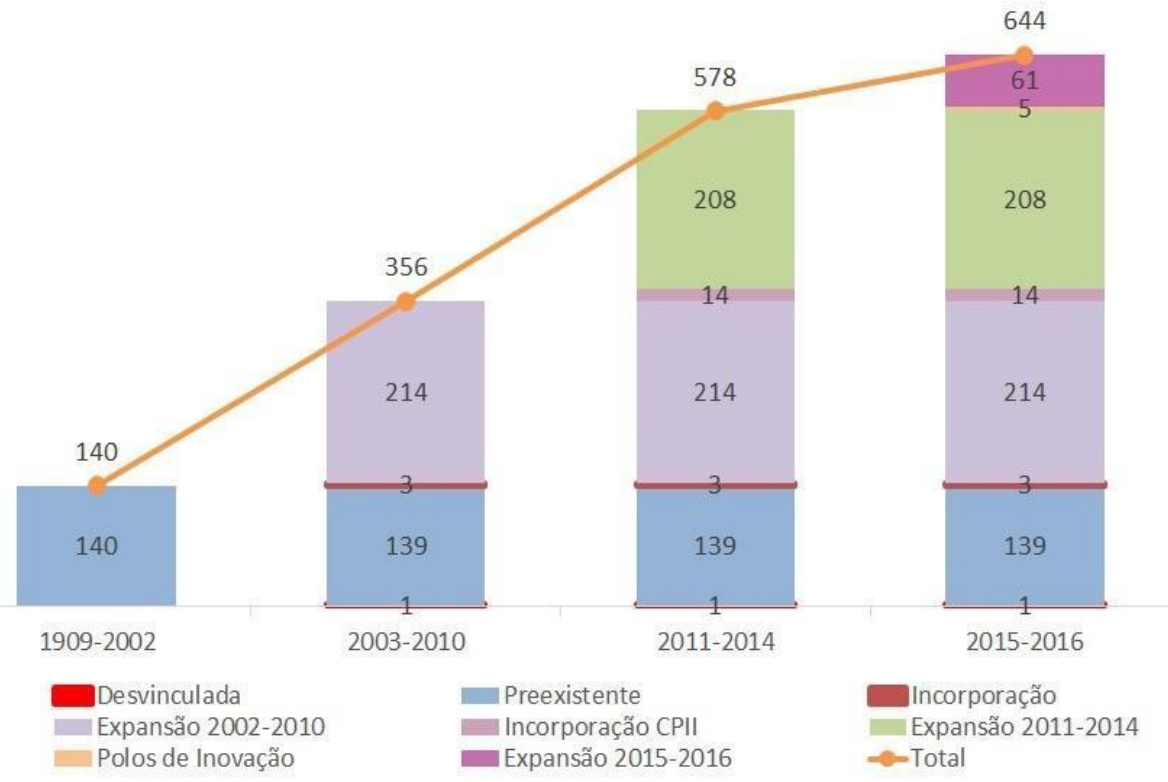

Fonte: http://redefederal.mec.gov.br/expansao-da-rede-federal

Figura 3 - Quantidade de municípios atendidos com a expansão da Rede Federal de Educação Profissional, Científica e Tecnológica

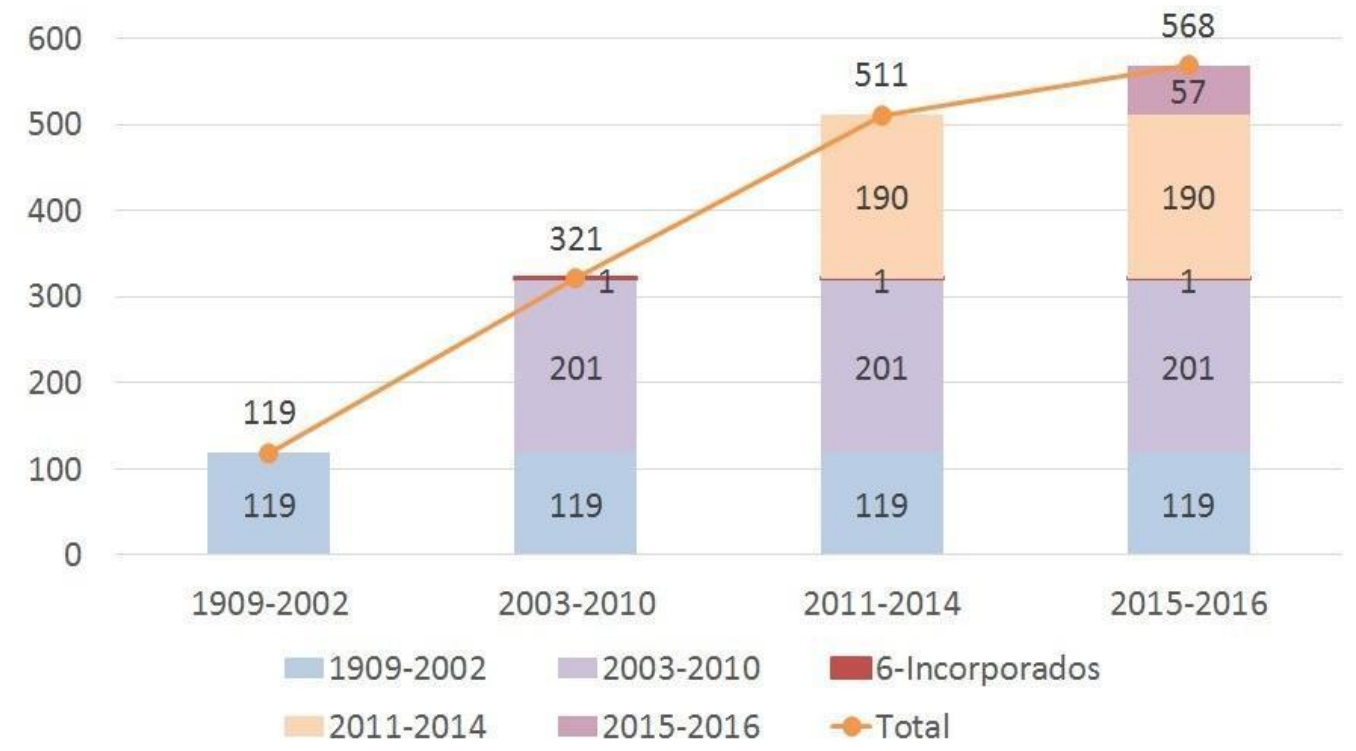

Fonte: http://redefederal.mec.gov.br/expansao-da-rede-federal

A educação profissional e tecnológica apresenta em suas diretrizes ${ }^{5}$ e concepções uma proposta de formação integral dos estudantes. Entre seus princípios norteadores, estão também o respeito aos valores estéticos, políticos e éticos da educação nacional, na perspectiva do desenvolvimento para a vida social e profissional. A dimensão profissional assume o trabalho como princípio educativo, na aproximação e integração dos conhecimentos gerais e específicos.

\footnotetext{
${ }^{5}$ Para aprofundamento, cabe a leitura da Resolução nº 6, de 20 de setembro de 2012, a qual define as Diretrizes Curriculares Nacionais para a Educação Profissional Técnica de Nível Médio (BRASIL, 2012).
} 
Diante do exposto, para Tavares (2012), contudo, o Estado realiza, contraditoriamente, mais uma bifurcação no sistema educacional brasileiro. Se no ensino secundário o estudante já se deparava com dois caminhos, o da preparação para o vestibular e o da profissionalização, parece que a criação de Institutos Federais ocasionou este mesmo processo no ensino superior ${ }^{6}$. Devido à trajetória recente dos IFs, ainda não é possível inferir se estes dois caminhos se apresentarão como escolas diferentes para classes sociais distintas ou se futuramente serão instituições de ensino equivalentes e equiparadas em termos de condições de acesso pelos estudantes, qualidade do ensino e finalidade institucional.

\subsection{Instituto Federal Farroupilha}

O Instituto Federal Farroupilha (IFFar) foi criado a partir da Lei no 11.892/2008, mediante a integração do Centro Federal de Educação Tecnológica de São Vicente do Sul com sua Unidade Descentralizada de Júlio de Castilhos e da Escola Agrotécnica Federal de Alegrete, além de uma Unidade Descentralizada de Ensino que pertencia ao Centro Federal de Educação Tecnológica de Bento Gonçalves, situada no Município de Santo Augusto. Assim, o IFFar teve na sua origem quatro campi: Campus São Vicente do Sul, Campus Júlio de Castilhos, Campus Alegrete e Campus Santo Augusto.

No ano de 2010, o IFFar expandiu-se com a criação do Campus Panambi, Campus Santa Rosa e Campus São Borja; no ano de 2012, com a transformação do Núcleo Avançado de Jaguari em Campus e, em 2013, com a criação do Campus Santo Ângelo e com a implantação do Campus Avançado de Uruguaiana. Em 2014 foi incorporado ao IFFar o Colégio Agrícola de Frederico Westphalen, que passou a se chamar Campus Frederico Westphalen, e foram instituídos seis Centros de Referência nas cidades de São Gabriel, Santa Cruz do Sul, Não-Me-Toque, Quaraí, Carazinho, Rosário do Sul e Santiago (IFFAR, 2014).

Assim, o IFFar constitui-se por dez campi e um Campus Avançado, em que ofertam cursos de formação inicial e continuada, cursos técnicos de nível médio, cursos superiores e cursos de pósgraduação, além de outros programas educacionais fomentados pela Secretaria de Educação Profissional e Tecnológica (SETEC). Além desses campi, o IFFar atua em 35 cidades do estado, com 37 polos que ofertam cursos técnicos na modalidade de ensino a distância (IFFAR, 2014).

A Reitoria do IFFar está localizada na cidade de Santa Maria/RS, a fim de garantir condições adequadas para a gestão institucional, facilitando a comunicação e integração entre os campi. Como autarquia, o IFFar possui autonomia administrativa, patrimonial, financeira, didático-pedagógica e disciplinar, atuando na oferta de educação superior, básica e profissional, pluricurricular e multicampi, especializada na oferta de educação profissional e tecnológica nas diferentes modalidades de ensino. Nesse sentido, os Institutos são equiparados às universidades, como instituições acreditadoras e certificadoras de competências profissionais, além de detentoras de autonomia universitária (IFFAR, 2014).

\footnotetext{
${ }^{6}$ Ver Resolução CNE/CP no 3, de 18 de dezembro 2002, a qual institui as Diretrizes Curriculares Nacionais Gerais para a organização e o funcionamento dos cursos superiores de tecnologia, com fundamento no Parecer CNE/CP no 29/2002 (BRASIL, 2002).
} 
Com essa abrangência, o IFFar visa à interiorização da oferta de educação pública e de qualidade, atuando no desenvolvimento local a partir da oferta de cursos voltados para os arranjos produtivos, culturais, sociais e educacionais da região. Assim, o IFFar, com sua recente trajetória institucional, busca perseguir este propósito, visando constituir-se em referência na oferta de educação profissional e tecnológica, comprometida com as realidades locais (IFFAR, 2014).

O IFFar é uma instituição de ensino pública e gratuita e, em atenção aos arranjos produtivos sociais e culturais locais, oferece cursos de formação inicial e continuada para trabalhadores, cursos técnicos de nível médio (presenciais e a distância) e cursos de graduação e pós-graduação, proporcionando a verticalização do ensino. A atuação pedagógica está voltada para a plena formação do cidadãoprofissional, perpassando pela articulação ensino-pesquisa-extensão (IFFAR, 2014).

A Reitoria do IFFar é composta por cinco Pró-Reitorias: de Administração, de Ensino, de Extensão, de Pesquisa, Pós-Graduação e Inovação e de Planejamento e Desenvolvimento Institucional. As ações de todas as Pró-Reitorias devem estar em consonância com as diretrizes educacionais brasileiras e promover a articulação entre ensino, pesquisa e extensão (IFFAR, 2014).

Nesse sentido, cabe destacar a missão do IFFar, que consiste em promover a educação profissional, científica e tecnológica, pública, por meio do ensino, pesquisa e extensão, com foco na formação integral do cidadão e no desenvolvimento sustentável. Para tanto, é objetivo da instituição ser excelência na formação de técnicos de nível médio e professores para a educação básica e em inovação e extensão tecnológica, respaldada em valores como: ética, solidariedade, responsabilidade social e ambiental, comprometimento, transparência, respeito e gestão democrática (IFFAR, 2014).

\subsection{O Programa Nacional de Assistência Estudantil (PNAES): gênese, regulamento e gestão}

O Programa Nacional da Assistência Estudantil (PNAES) foi instituído pela Portaria Normativa do Ministério da Educação (MEC) de 12 de dezembro de 2007 e regulamentado pelo Decreto n 7.234 no dia 19 julho de 2010. Constituído com o objetivo de ampliar as condições de permanência dos estudantes das Instituições de Ensino Superior (IES), considerando a necessidade de minimizar as desigualdades de oportunidades, contribuindo para melhoria do desempenho escolar agindo em ações preventivas de retenção e evasão decorrentes da insuficiência de condições financeiras.

As IES foram implantadas no nível de território nacional - pelo menos uma em cada estado - a partir da década de 60 do século XX. Entretanto, a expansão do ensino superior se deu 10 anos depois em função do processo de industrialização e de urbanização do país, que exigia a qualificação de mão de obra especializada. Tal expansão ocasionou dificuldades no processo de fiscalização, resultando na perda da qualidade de ensino, indo de encontro ao que prega a Reforma do Ensino Superior, Lei $n^{0}$ 5.540/68 (BRASIL, 1968), que regulamenta a organização e funcionamento de novas universidades.

Embora organizadas sob as normas impostas pela ditadura militar, as IES se desenvolveram tanto no nível de pesquisa como na área de pós-graduação. A partir dos anos 80 , com a crise de desaceleração econômica, ocorreu uma queda no repasse de recursos e, consequentemente, a contenção no processo de expansão das universidades. Por outro lado, sob o ponto de vista político, formaram-se inúmeras entidades populares fruto de grandes mobilizações sociais no momento em se abria uma nova fase histórica para o país, através do fim da ditadura e da promulgação da Constituição de 1988. 
É nesse espaço, nesse momento histórico, que se ligam os movimentos sociais que lutam pelo fim da ditadura, pela promulgação da Constituição de 1988, constituída com base na garantia de importantes direitos à cidadania para a população brasileira. Dentre os movimentos sociais está o movimento estudantil junto à evolução histórica da Assistência Estudantil (AE), onde inicialmente os programas eram oferecidos de forma fragmentada e pontual pela escassez de recursos destinados para tal fim, sem continuidade.

Emergem também, em meio à repressão do sistema político da época, duas importantes frentes políticas de discussões sobre as questões educacionais, em especial sobre questões relativas à educação e à assistência estudantil, o Fórum Nacional de Pró-Reitores de Assuntos Comunitários e Estudantis (FONAPRACE) em 1987, e a Associação Nacional dos Dirigentes das Instituições Federais de Ensino Superior (ANDIFES) - constituída em 1989. Defendiam a integração regional e nacional das instituições de ensino superior, com objetivo de garantir a igualdade de oportunidades aos estudantes das Instituições Federais de Ensino Superior na perspectiva do direito social, além de proporcionar aos estudantes as condições básicas para sua permanência e conclusão dos cursos, contribuindo e prevenindo a retenção e a evasão escolar decorrentes das dificuldades socioeconômicas dos alunos de baixa condição socioeconômica (ANDIFES, 2017).

Atuando até os dias de hoje, a ANDIFES é a representante oficial das universidades federais na interlocução com o governo federal, com as associações de professores, de técnico-administrativos, de estudantes e com a sociedade em geral. O FONAPRACE congrega os pró-reitores, sub-reitores, decanos ou responsáveis pelos assuntos comunitários e estudantis das Instituições de Ensino Superior (IES) públicas do Brasil (ANDIFES, 2017).

A partir da Constituição de 1988, com a garantia dos direitos sociais e do acesso universal à educação, encontram-se os fundamentos para justificar e buscar a legitimidade da AE nas Instituições de Ensino Superior. A LDB de 1990 também oferece amparo legal para a AE. Porém, a partir dessa década travou-se uma luta contra a ofensiva neoliberal e sua política de limitação de recursos para investimento no Ensino Superior Público, culminando com a LDB de 1996, que apresenta, em seu artigo 71, inciso IV, a desresponsabilização do Estado: "[...] não constituirão despesas de manutenção e de desenvolvimento do ensino, aquelas realizadas com: IV - Programas suplementares de alimentação, assistência médico-odontológica, farmacêutica e psicológica, e outras formas de assistência social" (BRASIL, 1996).

A partir desse quadro, o FONAPRACE realiza pesquisas sobre o perfil socioeconômico e cultural dos estudantes das IES nos anos de 1997, 2004 e 2011 a fim de, por meio dos indicadores sociais, iniciar um processo de discussão junto ao Ministério da Educação objetivando a implantação de uma política de $A E$. Em resposta às proposições e as lutas estudantis, é instituído, por meio da Portaria n 39 de dezembro de 2007, o Programa Nacional de Assistência Estudantil, sendo transformado em DecretoLei no 7.234/2010 no governo Lula, considerando-se "[...] um grande passo para que o PNAES saísse da dimensão de política de governo para política de Estado" (FONAPRACE, 2012, p. 62). O PNAES é na atualidade o documento norteador das políticas de assistência aos estudantes das IES, embasando os regulamentos e a gestão da política.

No IFFar, a Política de Assistência Estudantil foi instituída em 2012, com a seguinte finalidade: "Estabelecer os objetivos, princípios e eixos que nortearão os programas, projetos e ações 
desenvolvidos nos campi, com o intuito de garantir a ampliação de acesso e a permanência dos estudantes até a conclusão do curso, minimizando a retenção e evasão" (IFFar, 2012).

Também é estabelecido na Política que os projetos, programas e ações planejados e nela inseridos são concebidos como direitos dos estudantes, devendo ser garantidos e financiados pela instituição. Da mesma forma, farão parte do orçamento da Assistência Estudantil outros recursos federais repassados ao Instituto para este fim, como, por exemplo, o do PNAES.

Os recursos destinados à $A E$ são calculados pelo $M E C$ de acordo com o número de estudantes matriculados na IES. No IFFar os recursos são descentralizados para os campi também de acordo com o número de estudantes matriculados. Em cada campusa Coordenação da Assistência Estudantil, juntamente com a Direção Geral, programa a distribuição dos recursos de acordo com sua realidade e necessidade, podendo abranger as áreas de atenção à saúde, alimentação, cultura e esporte, auxílios financeiros e moradia estudantil.

As ações referentes à saúde são desenvolvidas de maneira articulada com os demais setores da instituição e rede local, voltadas à prevenção a doenças e promoção da saúde, tendo em vista as necessidades do discente como ser integral. São ações de saúde: serviço de psicologia, odontologia, enfermagem, médico e nutricional.

A segurança alimentar e nutricional objetiva garantir o acesso igualitário aos refeitórios e à alimentação adequada, possibilitar aos estudantes acesso à alimentação no período em que estão no Instituto. Assim como sensibilizar a comunidade escolar quanto à importância de ter uma alimentação saudável, disseminar informações sobre segurança alimentar e as formas de garanti-la.

No que diz respeito à cultura, as ações visam promover a formação integral dos estudantes, estimulando e desenvolvendo a criatividade, a reflexão crítica. As ações de esporte visam fomentar as práticas desportivas, a fim de garantir aos discentes o direito de acesso aos esportes e ao lazer na perspectiva da melhoria da qualidade de vida. No Instituto, todos os estudantes têm o direito de aprender e praticar esporte independente de condições físicas, de raça, cor, sexo, idade, orientação sexual, ou condição social.

Os auxílios financeiros têm como finalidade propiciar condições favoráveis à permanência e são destinados aos estudantes que comprovem estar em situação de vulnerabilidade socioeconômica e apresentem renda familiar per capita de até um salário mínimo e meio. 0 acesso aos auxílios permanência, transporte, à participação em eventos e estudante atleta acontece por meio de inscrições orientadas por editais.

A moradia estudantil tem como objetivo ofertar um espaço de residência junto ao campus, com condições básicas para o desenvolvimento acadêmico dos estudantes, visando garantir a permanência e prevenir a evasão estudantil, sendo destinada prioritariamente aos estudantes em situação de vulnerabilidade socioeconômica, menores de idade e que residam em locais de difícil acesso ao campus. Está disponível nos campi de Alegrete, Jaguari, Frederico Westphalen, São Borja e São Vicente do Sul.

As áreas da saúde, cultura, esporte e lazer e apoio didático pedagógico são voltadas para todos os estudantes. Já as diferentes modalidades de auxílio financeiro e moradia estudantil se destinam aos estudantes em situação de maior vulnerabilidade, identificados através de avaliação socioeconômica. 
Segundo Relatório de Análise de Gestão do MEC, 57\% dos estudantes matriculados no IFFar estão na faixa de renda familiar per capita de até 1,5 salários mínimos. Este percentual de estudantes tem direito a todos os programas e ações da Assistência Estudantil, porém os recursos repassados pelo MEC atendem aproximadamente $50 \%$ da demanda (BRASIL, 2015, p. 23).

Diante do exposto, é possível verificar o quanto o PNAES foi e ainda é objeto de luta tanto de dirigentes, mas principalmente dos próprios estudantes, em vista da sua relevante contribuição para o acesso, permanência e êxito destes sujeitos em suas trajetórias formativas. Assim, este artigo procura explicitar a necessidade de os servidores que compõem os quadros funcionais do IFFar conhecerem o percurso histórico da Educação Profissional e Tecnológica Brasileira, seus objetivos e princípios, para que possam, assim, compreender as políticas e programas por ela assumidos, em especial aqui o PNAES.

Acredita-se na necessidade de uma formação para os servidores no estudo deste programa, principalmente pelo desconhecimento de alguns, ou até mesmo uma compreensão equivocada de outros. Com isso, o objetivo maior é que todos construam juntos este conhecimento e que possam, se for o caso, (res)significar suas concepções e práticas.

\section{PNAES E OS SERVIDORES DO IFFAR: UMA PROPOSTA DE FORMAÇÃO CONTINUADA}

Este tópico aborda a necessidade da formação dos servidores em educação, em específico a formação continuada em serviço. Para tanto, apresenta algumas considerações acerca de uma prática inovadora frente a um paradigma emergente (BEHRENS, 2013), e a necessidade de um processo de reflexão na ação (SCHÖN, 1995). E, para finalizar, apresenta uma proposta de formação continuada, destinada não apenas aos professores, mas a todos os servidores do IFFar, com vistas a conhecerem este importante programa denominado PNAES, possibilitar a autoformação (FERRY, 1997) e com isso a construção da identidade profissional, baseada na ética e na educação como responsabilidade diante do outro (TARDIF, 2013).

Estamos inseridos em uma sociedade em constante transformação, as descobertas científicotecnológicas ocorrem em um ritmo nunca antes experimentado, modificando, assim, as configurações e relações sociais. As instituições educacionais necessitam, portanto, investir na formação continuada de seus servidores, pois é urgente um (re)pensar das práticas pedagógicas.

O paradigma positivista, conservador, que dominou a sociedade e por consequência a educação, perde cada vez mais espaço, tendo em vista a necessidade de sujeitos mais criativos e críticos, que possam atuar com autonomia frente a esta sociedade em constante transformação. Daí a necessidade de pensar a formação de todos os trabalhadores em educação, pelo viés de paradigmas inovadores que contemplem o ensino e a aprendizagem com o objetivo de produção do conhecimento, e para tanto cabe trazer a abordagem sistêmica, pois, de acordo com Behrens (2013):

A forte influência de avanço paradigmático na ciência levou a uma nova visão para o mundo, para a educação e para a prática pedagógica. [...] A dimensão que se pretende com uma perspectiva sistêmica ou holística é que o homem recupere a visão do todo. Que se sinta pleno, vivendo dentro da sociedade como um cidadão do mundo e não como um ser isolado em sua própria individualidade (p. 58). 
Nesse sentido, a abordagem sistêmica permite que se construa uma formação, neste caso de docentes e técnicos em educação, que considere o sujeito como um todo. Intenciona-se, assim, a superação da visão fragmentada da educação, ainda tão presente nas instituições de educação básica e superior. Diante disso, busca-se uma proposta de formação não apenas para os docentes, mas para todos os profissionais da educação, uma vez que este é um processo tecido por diversas mãos, sendo que no IFFar cada servidor desempenha, dentro de suas atribuições específicas, uma função educativa, e necessita, portanto, de espaços de formação.

A formação aqui pretendida baseia-se nos estudos de Ferry (1997), quando este pontua que ela acontece para além do profissional, sendo uma dinâmica do desenvolvimento pessoal dos sujeitos. Portanto, esta formação é mediada pela relação com o(s) outro(s), pelas leituras, circunstâncias da vida, as condições de lugar e a realidade onde se está inserido, são todos estes aspectos que constituem o profissional.

Desse modo, segundo Ferry (1997), não se recebe uma formação como um processo alheio ao indivíduo. Para o autor, ninguém pode formar o outro, o indivíduo forma-se a si próprio, em um processo de autoformação e heteroformação:

[...] tocamos lo que hace a lo esencial de la formación, es decir, la relación entre la autoformación y la heteroformación. Nosotros principalmente tenemos la idea de una formación cuya parte activa se representa del lado del establecimiento y del maestro, y la pasiva del lado del sujeto que está en formación. Con respecto a esto, hay una palabra a la que soy totalmente alérgico, es la palabra "formado". El "formador" y el "formado" [...] Es horrible! (FERRY, 1997, p. 93, grifo do autor)7.

Nessa perspectiva, a formação assume uma relação dinâmica entre todos os sujeitos. Nesse sentido, é um integrar de conhecimentos e experiências, em uma construção ativa do indivíduo e com o grupo. Deste modo, o propósito da formação não segue um único modelo, tem em vista um diálogo, onde ocorra a alternância entre a formação prática e a formação teórica. Não se concebe, portanto, um formador para este processo, mas uma relação de troca entre os servidores docentes e técnicos, onde cada contribuição é valiosa e formativa.

Com isso, reporta-se, a Tardif (2013) quando este enfatiza que a formação docente é uma amálgama de saberes, nela situam-se conhecimentos, competências, habilidades, atitudes. Existem, portanto, diferentes saberes, os disciplinares, curriculares, profissionais e experienciais, que constituem a identidade profissional. Entende-se que as contribuições de Tardif (2013), em específico para prática docente, cabem perfeitamente para os demais servidores em educação do IFFar, visto que, como já salientado, desempenha-se também o papel formativo nas diferentes funções. Como atores sociais e éticos, é importante salientar:

A pedagogia não pode ser outra coisa senão a prática de um profissional, isto é, de uma pessoa autônoma, guiada por uma ética do trabalho e confrontada diariamente com problemas para os quais não existem receitas prontas. Um profissional do ensino é alguém que deve habitar e construir seu próprio espaço pedagógico de trabalho de acordo com limitações complexas que só ele pode assumir e resolver de maneira

\footnotetext{
7 Tradução: "[...] tocamos no que é o essencial da formação, ou seja, a relação entre autoformação e heteroformação. Nós principalmente temos a ideia de uma formação cuja parte ativa é representada no lado do estabelecimento e do professor, e o passivo no lado do sujeito que está em formação. Com relação a isso, há uma palavra para a qual sou totalmente alérgico, é a palavra "formado". O "formador" e o "formado"... É horrível!"
} 
cotidiana, apoiado necessariamente em uma visão de mundo, de homem e de sociedade (TARDIF, 2013, p. 149).

Os autores aqui citados apresentam inegáveis contribuições para a formação docente, e ousa-se pensar que também para os demais profissionais da educação. Quando se aponta para a necessidade de uma mudança paradigmática, tendo em vista uma visão sistêmica, que propicie uma atuação autônoma, isto se aplica a todos os sujeitos que fazem a educação. Da mesma forma, percebe-se que este processo ocorre por meio do desenvolvimento pessoal, da autoformação ${ }^{8}$, como também, nas diversas relações com os outros e com a sociedade, perpassadas sempre pela pluralidade de saberes que constituem a trajetória formativa de todos os profissionais.

Frente a estas considerações, apresenta-se uma proposta de formação continuada para todos os servidores, preferencialmente os ligados à Direção de Ensino, nos espaços e tempos destinados à formação já instituídos nos Campi do IFFar. Para tanto, esta proposta será inicialmente apresentada à Reitoria da instituição, com o intuito de que venha a se constituir uma política institucional em vista da necessidade e da importância de que os servidores conheçam o programa PNAES.

Compreender que políticas públicas são formuladas por um conjunto de diretrizes legalmente embasadas e que se concretizam por meio de serviços ou programas que objetivam a promoção ou garantia de direitos nem sempre é simples, ou percebido com clareza. A assistência estudantil como um direito assegurado pelo PNAES também é, muitas vezes, entendida como caridade, generosidade e compaixão. É uma concepção alienada da realidade que necessita ser ponderada e refletida com formações, informações e a demonstração do compromisso com a integração social, oferta de serviços e distribuição de renda de forma justa aos sujeitos em situação de maior vulnerabilidade, por meio de uma ação consciente e responsável.

Como metodologia de trabalho será proposta a construção de um grupo de formação. A opção pelo trabalho em grupo baseia-se nas características dos sujeitos em formação, visto ser um público diverso, que compreende docentes e técnicos, e daí a necessidade de uma ferramenta que permita maior liberdade e interação entre os sujeitos. Com o grupo de formação será possibilitado o diálogo, constituindo-se um espaço de formação com a troca de saberes, experiências, dúvidas e anseios.

Desse modo, a perspectiva do trabalho em grupo, quando se trata de espaços de formação, envolve tanto a dimensão pessoal quanto a profissional de cada participante, pois tanto as subjetividades, como os sentimentos, desejos, dúvidas e aspirações, assim como as opiniões, conhecimentos e concepções fazem parte da estratégia de aprendizagem. Com isso, para Ferry (1997), o trabalho em grupo é a melhor dinâmica para um público de adultos, seja qual for o objetivo da formação, uma vez que oferece possibilidades de expressão individual das aspirações e dificuldades, sendo base para a cooperação com os outros sujeitos em formação.

\footnotetext{
${ }^{8}$ Ferry (1997) utiliza o conceito de autoformação para desenvolver a ideia de uma atitude ativa no que se refere à formação, pois para o autor não é um formador que dá forma a um sujeito, mas é o sujeito o construtor de sua formação, isto, pois, não é um processo externo, mas, sim, um processo interno de autoformação. Deste modo, para Ferry (1997) formar-se é transformar-se em contato com a realidade, e durante este processo de formação ser capaz de conduzir sua própria formação.
} 
A dinâmica da proposta de formação continuada ocorrerá nas seguintes etapas, descritas abaixo:

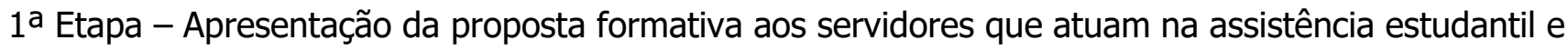
no setor de apoio pedagógico, e posteriormente aos demais servidores. Em seguida, após concordância em participar da formação, a constituição dos grupos (serão constituídos grupos de dez a quinze pessoas), conforme o número de servidores do campus, com representatividade de docentes e técnicos em ambos. Inicialmente, foi definido que os encontros ocorrerão quinzenalmente, nos turnos das reuniões de formação já estipulados em calendário institucional, com duração de noventa minutos, por aproximadamente dois meses.

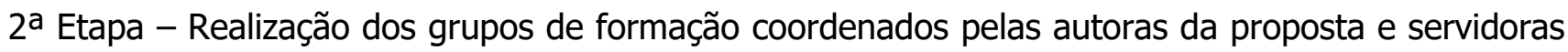
do IFFar. Nesta etapa será possibilitado que cada membro relate como se deu o ingresso na instituição (o porquê desta escolha, seus anseios e objetivos, o percurso formativo e a função como servidor do IFFar). Este momento de escuta configura-se de extrema relevância, uma vez que permite que as experiências pessoais sejam compartilhadas.

$3^{a}$ Etapa - Após o relato das experiências formativas dos servidores, será oportunizado o diálogo acerca do conhecimento que os sujeitos participantes possuem da Rede Federal de Educação Profissional e Tecnológica (RFEPT), das políticas e programas que dela fazem parte, em especial o PNAES. Neste momento, os servidores irão expor e debater nos grupos o conhecimento, a visão e as concepções que possuem acerca das temáticas referidas acima, dentre elas: educação profissional, criação da RFEPT, políticas e programas desenvolvidos, com ênfase ao PNAES. No andamento destas atividades serão inter-relacionados os conhecimentos manifestados pelos servidores com os materiais pesquisados e disponibilizados ao grupo pelas coordenadoras (marcos legais e normativos, aporte teórico-metodológico).

4a Etapa - Serão convidados para participar os gestores do Programa PNAES (servidores do setor administrativo e da assistência estudantil), para traçar um panorama geral e explicitar como o programa é estruturado na instituição, principalmente no que diz respeito aos recursos financeiros para sua execução, qual o público alvo, como acontece a seleção dos sujeitos e com que objetivos. Da mesma forma será oportunizado o diálogo com uma representação dos estudantes beneficiários do PNAES com o objetivo de ouvir dos sujeitos que dele fazem parte se há e quais são as contribuições que o programa traz para seus itinerários formativos.

É importante destacar que o número de encontros das etapas anteriores dependerá das demandas e necessidades do grupo de formação, no sentido de respeitar as singularidades e as particularidades das questões pessoais e profissionais de cada professor e técnico, de acordo com cada etapa.

$5^{a}$ Etapa - No último encontro do grupo será analisado o percurso formativo desta formação, ou seja, a intenção é promover uma reflexão sobre em que medida os encontros do grupo de formação contribuíram para a prática profissional, se os conhecimentos e concepções foram de alguma forma (trans)formados, um processo de efetiva reflexão.

6a Etapa - No decorrer do ano letivo, após a finalização destas atividades, será solicitado espaço para que, durante algumas reuniões gerais e pedagógicas, os servidores que participaram da proposta possam relatar a todo o grupo "se" e "como" a formação contribuiu para o desenvolvimento e o (re)pensar de suas práticas nos diferentes espaços institucionais em que atuam. 
Assim, acredita-se que a proposta de formação continuada, embasada nos aportes teóricos acima citados, é uma das possibilidades para a mudança de um paradigma conservador, para uma visão holística da educação. A construção de outros caminhos é possível, a dinâmica do grupo de formação será o instrumento que viabilizará a partilha de conhecimentos, experiências, informações e o desenvolvimento de um pensar crítico e reflexivo.

Desse modo, reporta-se a Nóvoa (1995) quando este enfatiza uma profissão docente construída na perspectiva crítico-reflexiva de autoformação, por meio de um pensamento autônomo que permita, como defende o autor, uma práxis como produção do saber. Para tanto, aponta o desenvolvimento pessoal, o desenvolvimento profissional e o desenvolvimento organizacional. Estes aspectos trazidos por Nóvoa (1995) permitem compreender que a formação docente é um processo amplo, que envolve pelo menos três dimensões: as experiências de vida, a formação como profissional e a instituição da qual se faz parte.

\section{METODOLOGIA}

Para o presente estudo optou-se pela abordagem qualitativa. Tal opção baseia-se por acreditar que o trabalho científico na área das ciências humanas pressupõe uma relação dinâmica entre pesquisador e objeto de estudo, em que contexto e tempo precisam ser considerados, pois seu ambiente é a vida real, e os fatos a serem interpretados são significados sociais (MICHEL, 2015). Tal metodologia justifica-se, por esta investigação desenvolver-se em uma instituição de ensino composta por sujeitos em formação, tanto servidores quanto estudantes, e em que as autoras também compõem o quadro funcional, portanto, acredita-se que uma pesquisa de cunho qualitativo seja a opção mais condizente.

Nesse sentido, apoiado na abordagem qualitativa, o estudo caracteriza-se por uma análise documental e uma pesquisa bibliográfica. Os documentos analisados, fontes da pesquisa, foram os marcos regulatórios que normatizam a educação profissional brasileira, e o aporte teórico fundamentado em obras que tratam sobre políticas educacionais e história da educação profissional brasileira ao longo de sua implementação, com destaque para: Akkari (2011), Pacheco (2010) e Tavares (2012). Também estão presentes, neste estudo, autores que tematizam a formação de professores, como: Behrens (2013), Ferry (1997), Tardif (2013), Schön (1995) e Nóvoa (1995), os quais fundamentaram a proposta de uma formação continuada destinada a todos os servidores que estejam envolvidos nos processos educativos.

\section{CONSIDERAÇÕES FINAIS}

Ao considerar o processo histórico da organização da educação no Brasil desde os anos de 1909 aos de 2000, percebe-se que os caminhos percorridos se caracterizam pela oferta de ensino distinto para classes sociais diferentes, para uns o direito à escolha do caminho a percorrer, para outros apenas um caminho. Nota-se também que na última década houve mudanças nas políticas sociais e educacionais com o intuito de ofertar ensino de qualidade como direito para todos, independente da classe social. Como parte desta política de inclusão surgem os Institutos Federais equiparados e com autonomia universitária, com a proposta de promover o ensino em sintonia com as demandas dos arranjos produtivos locais e com um quadro de servidores formado por docentes e técnicos. 
Embora com suas particularidades, os IFs guardam semelhanças com outras instituições de ensino ou com seus quadros de docentes, percebidas por meio da pesquisa das obras dos célebres autores citados acima e que iluminaram este estudo. É deste modo que se conclui e se acredita na importância da formação continuada para todos os servidores da educação profissional.

Abordou-se, neste texto, especificamente o Programa Nacional de Assistência Estudantil (PNAES) ligado diretamente aos estudantes do IFFar, e também a necessidade de os servidores compreenderem seus objetivos, sua gestão e suas implicações para o acesso e a permanência dos mesmos. Para tanto, apresentou-se uma proposta de formação continuada observando os argumentos dos autores estudados que tematizam acerca dos processos formativos, autoformativos e reflexivos. Desta sugestão, espera-se que novas propostas e pesquisas aconteçam no sentido de aperfeiçoar os processos de formação e, por consequência, os processos de ensino e aprendizagem envolvendo toda a comunidade escolar.

\section{REFERÊNCIAS}

\section{Livros:}

AKKARI, A. Internacionalização das políticas educacionais: transformações e desafios. Petrópolis, RJ: Vozes, 2011.

ARAPIRACA, J. O. A USAID e a Educação brasileira. São Paulo: Autores Associados: Cortez, 1982. BEHRENS, M. A. O paradigma emergente e a prática pedagógica. Petrópolis, RJ: Vozes, 2013. FERRY, G. Pedagogia de la formación. Buenos Aires: Ediciones Novedades Educativas, 1997.

MICHEL, M. H. Metodologia e pesquisa em ciências sociais: um guia prático para acompanhamento da disciplina e elaboração de trabalhos monográficos. 3.ed. São Paulo: Atlas, 2015.

NÓVOA, A. Os professores e a sua formação (Coord.). Portugal: Publicações Dom Quixote, 1995.

PACHECO, E. Os Institutos Federais: uma Revolução na Educação Profissional e Tecnológica. Natal: IFRN, 2010.

PERONI, V. Política educacional e papel do Estado: no Brasil dos anos 1990. São Paulo: Xamã, 2003.

SCHÖN, D.A. Formar professores como profissionais reflexivos. In: NÓVOA, A. Os professores e a sua formação (Coord.). Portugal: Publicações Dom Quixote, 1995.

TARDIF. M. Saberes docentes e formação profissional. Petrópolis, RJ: Vozes, 2013.

\section{Periódico:}

LIBÂNEO, J. C. O dualismo perverso da escola pública brasileira: escola do conhecimento para os ricos, escola do acolhimento social para os pobres. Educação e Pesquisa, São Paulo: v. 38, n. 1, p. 13-28, jan./jun., 2012.

\section{Documentos eletrônicos:}

ASSOCIAÇÃO NACIONAL DOS DIRIGENTES DE INSTITUIÇÕES FEDERAIS DE ENSINO SUPERIOR (ANDIFES). Estatuto da Associação dos Dirigentes de Instituições Federais de Ensino 
Superior. Disponível em: <http://www.andifes.org.br/institucional/a-andifes/>. Acesso em 12 jun. 2017.

ASSOCIAÇÃO NACIONAL DOS DIRIGENTES DE INSTITUIÇÕES FEDERAIS DE ENSINO SUPERIOR (ANDIFES). Fórum Nacional de Pró-reitores de Assuntos Comunitários e Estudantis. Disponível em: <http://www.andifes.org.br/forum-nacional-de-pro-reitores-de-assuntoscomunitarios-e-estudantis-fonaprace/>. Acesso em 12 jun. 2017.

ASSOCIAÇÃO NACIONAL DOS DIRIGENTES DE INSTITUIÇÕES FEDERAIS DE ENSINO SUPERIOR (ANDIFES). Relatório da Comissão Constituída pela Portaria n 126/2012 sobre a Análise da Expansão das Universidades Federais - 2003 a 2012. 2012. Disponível em: <http://www.andifes.org.br/wp-content/files_flutter/1361475592UFMT_-_Maria_Lucia_Neder__Relatorio_REUNI.pdf > Acesso em 08 jun. 2017.

BRASIL. Lei $\mathbf{n}^{\circ} \mathbf{5 . 5 4 0}$ de $\mathbf{2 8}$ de novembro de 1968. Fixa normas de organização e funcionamento do ensino superior e sua articulação com a escola média, e dá outras providências. Disponível em: <http://www.planalto.gov.br/ccivil_03/leis/L5540compilada.htm>. Acesso em 12 jun. 2017.

BRASIL. Lei no 9.394, de 20 de dezembro de 1996. Lei de Diretrizes e Bases da Educação - LDB. Estabelece as Diretrizes e Bases da educação nacional. Disponível em: <http://www.planalto.gov.br/ccivil_03/Leis/L9394.htm>. Acesso em 12 jun. 2017.

BRASIL. Ministério da Educação. Instituto Nacional de Estudos e Pesquisas Educacionais Anísio Teixeira. Censo da Educação Superior 2013: resumo técnico. Brasília, 2015. Disponível em: <http://download.inep.gov.br/download/superior/censo/2013/resumo_tecnico_censo_educacao_sup erior_2013.pdf > Acesso em 29 mai. 2017.

BRASIL. Ministério da Educação. Plano Nacional de Educação. PNE em Movimento. Disponível em: <http://pne.mec.gov.br/planos-de-educacao> Acesso em 25 jun. 2017.

BRASIL. Ministério da Educação. Portal Brasil. Surgimento das escolas técnicas. 2014. Disponível em:< http://www.brasil.gov.br/educacao/2011/10/surgimento-das-escolas-tecnicas > Acesso em 03 jun. 2017.

BRASIL. Ministério da Educação. Portal da Rede Federal de Educação Profissional, Científica e Tecnológica. Centenário da Rede Federal de Educação Profissional e Tecnológica. [2009?]. Disponível em: <http://portal.mec.gov.br/setec/arquivos/centenario/historico_educacao_profissional.pdf> Acesso em 31 mai. 2017.

BRASIL. Ministério da Educação. Portal da Rede Federal de Educação Profissional, Científica e Tecnológica. Expansão da rede federal. 2016. Disponível em: < http://redefederal.mec.gov.br/expansao-da-rede-federal> Acesso em 01 jun. 2017.

BRASIL. Ministério da Educação. Portal da Rede Federal de Educação Profissional, Científica e Tecnológica. Histórico. 2016. Disponível em <http://redefederal.mec.gov.br/historico> Acesso em 02 jun. 2017.

BRASIL. Ministério da Educação. Programa Nacional de Acesso ao Ensino Técnico e Emprego - PRONATEC. 2016 Disponível em: <http://pronatecportal.mec.gov.br/pronatec.html> Acesso em: 28 mai. 2017.

BRASIL. Ministério da Educação. Relatório Anual de Análise dos Indicadores de Gestão das Instituições Federais de Educação Profissional, Científica e Tecnológica. Exercício 2015. 
SETEC. Disponível em: <http://portal.mec.gov.br/docman/julho-2016-pdf/45621-setec-analise-deindicadores-2015-pdf/file>. Acesso em 10 jun. 2017.

BRASIL. Ministério da Educação. Secretaria de Educação Profissional e Tecnológica. Legislação e atos normativos. $\quad$ Resoluções. $2012 . \quad$ Disponível em: <http://portal.mec.gov.br/index.php?option=com_docman\&view=download\&alias=11663-rceb00612-pdf\&category_slug=setembro-2012-pdf\&Itemid=30192>. Acesso em 05 jul. 2017.

INSTITUTO FEDERAL FARROUPILHA (IFFar). Resolução no 12, de 30 de março de 2012. Política de Assistência $\quad$ Estudantil. $2012 . \quad$ Disponível em: <http://www.iffarroupilha.edu.br/assist\%C3\%AAncia-estudantil>. Acesso em 10 jun. 2017.

INSTITUTO FEDERAL FARROUPILHA (IFFar). Documentos Institucionais. Plano de Desenvolvimento Institucional- 2014-2018 (PDI). 2014. Disponível em: <http://w2.iffarroupilha.edu.br/site/midias/arquivos/2015324151055989pdi_14_18pdf.pdf>. Acesso em 02 jun. 2017.

SGUISSARDI, V. Modelo de expansão da educação superior no Brasil: predomínio privado/mercantil e desafios para a regulação e a formação universitária. Educ. Soc., Campinas, v. 29, n. 105, set./dez. 2008. Disponível em: <http://www.scielo.br/pdf/es/v29n105/v29n105a04.pdf > Acesso em 31 mai. 2017.

OBSERVATÓRIO DO PNE. Plano nacional de Educação. Disponível em:<http://www.observatoriodopne.org.br/metas-pne/11-educacao-profissional> Acesso em 02 de jul.2017.

TAVARES, M.G. Evolução da Rede Federal de Educação Profissional e Tecnológica: as etapas históricas da educação profissional no Brasil. In: IX ANPED SUL - Seminário de Pesquisa em Educação da Região Sul, Caxias do Sul. Rio Grande do Sul, 2012. Disponível em: <http://www.portalanpedsul.com.br/admin/uploads/2012/Estado_e_Politica_Educacional/Trabalho/0 1_08_10_177-6475-1-PB.pdf> Acesso em 08 jun. 2017. 